Atapattu, A.H.A.T.L., Abenayake, M., Dilakshan, R. and Sandupama, A.V.P.U., 2019. A framework for regulatory bodies to control informal building construction in Sri Lanka. In: Sandanayake, Y.G., Gunatilake, S. and Waidyasekara, A. (eds). Proceedings of the $8^{\text {th }}$ World Construction Symposium, Colombo, Sri Lanka, 8-10 November 2019, pp. 23-32. DOI: doi.org/10.31705/WCS.2019.3. Available at: https://2019.ciobwcs.com/papers

\title{
A FRAMEWORK FOR REGULATORY BODIES TO CONTROL INFORMAL BUILDING CONSTRUCTION IN SRI LANKA
}

\author{
A.H.A.T.L. Atapattu ${ }^{1}$, Mahesh Abenayake ${ }^{2}$, R. Dilakshan ${ }^{3}$ and \\ A.V.P.U. Sandupama ${ }^{4}$
}

\begin{abstract}
Socio financial and environmental affectability due to the construction improvements and its relativity with comprehension of building property advancement leads construction to become trendy activity in the society. In order to obtain the major roles in the economy of country construction conducted in to two segments called formal and informal. When render wider perspective on construction activities, there are highly considerable rate of failing, short coming, quality deficiencies etc. Building regulations facilitates to overcome and guarantee socially adequate levels of well-being, security, welfare and convenience for building tenants. This research undertaken using mixed method approach including pilot survey, questionnaire survey and expert interviews. From fifty (50) respondents to questionnaire survey, thirty eight (38) were identified as informal building constructions. It was employed to investigate the extend of obtaining the permits in building construction projects and discrepancies, deformations, laid significances on professional selection and considerations laid on design and construction stage. From the statistical analysis of the survey conducted identified addressable key areas to minimise informal construction activities, which causes deterioration in building constructions. In order to overcome that, eight (8) expert interviews were conducted among the professionals in relevant subject area. Gathered qualitative data were analysed using content analysis techniques. Consequently, the requirement of regulatory bodies to minimise the informal construction were identified which directly or indirectly influence positively on quality of buildings and defect free environment. Finally, framework demarcates the building informality, causation to building performance due to informal construction and building defects along with the remedial actions.
\end{abstract}

Keywords: Building Collapse; Building Defects; Informal constructions; Regulatory Bodies.

\section{INTRODUCTION}

Construction, renovation and maintenance works on buildings and infrastructures are categorised under the scope of construction sector in any country (Hughes et al., 2012). Further, buildings are used for many purposes such as residential, commercial,

\footnotetext{
${ }^{1}$ V.V Karunarathne \& Company, Sri Lanka, thilinaatapattu@gmail.com

${ }^{2}$ Department of Building Economics, University of Moratuwa, Sri Lanka, mabeynayake@uom.lk

${ }^{3}$ Department of Building Economics, University of Moratuwa, Sri Lanka,

dilakshanrajarathnam@gmail.com

${ }^{4}$ Lakshman Ramanayake \& Associates PVT Ltd, Sri Lanka, sandupamav@gmail.com
} 
institutional, educational, and industrial to obtain requirements of people (Adnam et al., 2009). Couple of year back the building construction industry in Sri Lanka began to present booming after passing the decades with terrorism and large disasters such as Tsunami (Chandrasena, 2010). Further, Chandrasena (2010) stated within recent period of time there are number of building construction projects arising and to be start due to the economic growth, resettlement and urbanisation. Due to the long-life cycle of the building involvement of different stakeholders in different phases of building are common in building projects (Konig and Cristofaro, 2012).

There are two types of building construction such as, formal building construction and informal building construction (Mlinga and Lema, 2011). The formal segment involving the traditional designers and the informal part comprising of improvised designers (Yeboah, 2012). Further, formal designers take after the acknowledged standards of acquiring endorsements and register with the Construction Industry Development Authority (CIDA) (Lerociyani et al., 2013). On the other hand, informal constructions are playing a major role in economy of developing countries by implementing more job opportunities to the range of unskilled to specialized workers and cheap approaches to achieve shelter even for the low-income level (Mlinga, 2001).

In developing countries, a major role in construction industry is fulfilled by informal construction sector (Wells, 2007). Importance of informal sector in less developed countries has been recognized by governments and international agencies (Gerxhani, 2004). As informal contractors are not registered in CIDA and informal contractors mainly engage in housing and building construction industry (CCI, 2017). According to Wells (2007) in developing countries, informal contractors carry out almost all construction in rural areas and 50\% of all construction in urban areas. Most informal contractors are individually owned and male dominated enterprises (Ahzahar et al., 2011). In addition to that, informal contractors mainly employ temporary workers who work on a casual basis and less permanent workers (Mlinga and Lema, 2011). Informal developers have problems in many categories (Ludlow and Neuhold, 2017). In order to obtain the building permit approval, it is probable that they get the signatures of an architect and an engineer to obtain the clearance from the local authority (Jewel et al., 2005).

The advantages and disadvantages of the informal construction industry can be derived in terms of economic, social and political factors. Accordingly, the cost of labour is relatively less in the informal sector when compared to the formal sector and consequently a downward pressure is exerted on the labour expenses in the formal market as well (Wetlesen, 2011). However, various deformation can be experienced in the major economic indicators such as the unemployment rate, inflation rate, due to the activities of the informal sector (Overa, 2004).

More employment opportunities are emerged to the society with the interference of the informal sector; therefore, the living conditions of the people are improved (Chong et al., 2008). On the other hand, the employees of the informal sector are not deemed to pay any taxes or other social security contributions, which may be unjust for the formal sector employees (Mlinga and Wells, 2002). Through the informal construction sector, the public dissatisfaction and the social tension that may arise due to the monopoly of the formal sector can be eliminated (Blades et al., 2011). As the informal sector activities may not always be included to the calculation of the Gross Domestic Product, or other 
economic indications, the incorrect statistics might provide a deceptive image to the policy and decision makers (Ludlow and Neuhold, 2017).

Even though, there is an issue regarding the informal construction activities (Sandaratne, 2002). Building regulations are legitimate instruments proposed to guarantee that structures, when built as per the controls, give socially adequate levels of wellbeing, security, welfare and convenience for building tenants (Pedro et al., 2009). Due to the absence of regulatory body to inspect the ongoing construction projects for the guarantee of ongoing construction is carrying on accordance with the relevant norms and standards specified (CCI, 2017). Thus, it creates more opportunities of building disasters such as collapsing in shorter period from the construction and therefore there is a requirement of providing proper regulative actions by the statutory bodies (CCI, 2017).

\section{RESEARCH METHODS}

First a semi-structured interview was conducted in order to validate the literature findings from a professional who involved with the building construction regulations. Then a questionnaire was distributed among 64 building owners in Central province with buildings less than four floors. Out of these, 50 responses were received. Due to the time constraints and accessibility buildings were selected from above mentioned area. Thereafter, eight un-structured expert interviews were conducted among professionals involved in the subject related area to identify suggestions to mitigate informal building constructions in Sri Lanka.

Types of the buildings: The sample comprises with $68 \%$ residential buildings, $26 \%$ commercial buildings and $6 \%$ of industrial buildings (refer Figure 1).

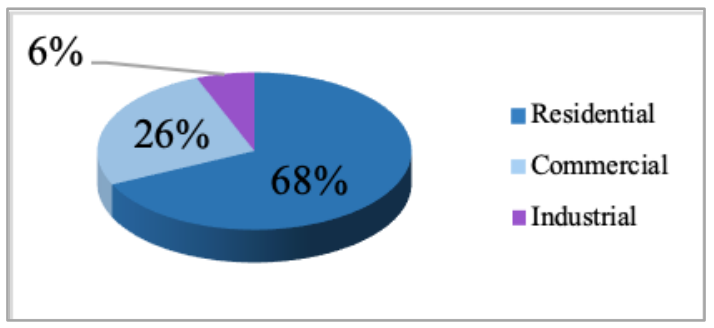

Figure 1: Types of buildings

Age of building: According to Figure 2, 14\% of the buildings age $0-10$ years, $36 \%$ of the buildings age $10-20$ years, $30 \%$ of the buildings age $20-30$ years, $12 \%$ of the buildings age $30-40$ years.

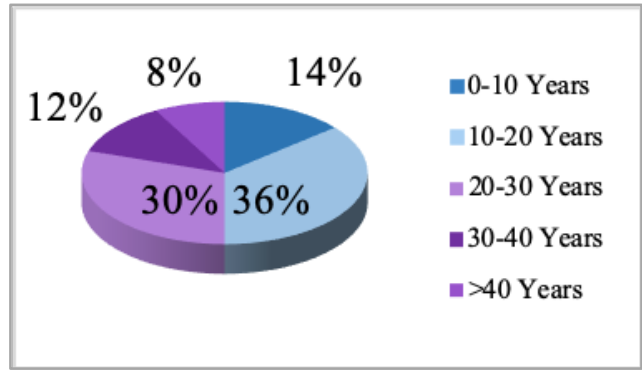

Figure 2: Age of buildings 
Expert interviews were conducted among eight professionals working in Sri Lanka related to the construction industry. The factors, which were discussed through expert interviews are further discussed under following sub sections.

Table 1: Details of interviewee participants

\begin{tabular}{clllc}
\hline $\begin{array}{c}\text { Interviewee } \\
\text { code }\end{array}$ & \multicolumn{1}{c}{ Profession } & $\begin{array}{c}\text { Type of } \\
\text { Organization }\end{array}$ & Designation & $\begin{array}{c}\text { Experience } \\
\text { (Years) }\end{array}$ \\
\hline IA & Administration & Regulatory & Deputy Director & 20 \\
IB & Administration & Regulatory & Deputy Director & 20 \\
IC & Chartered Arch. & Regulatory & Director & 25 \\
ID & Chartered Arch. & Regulatory & Deputy Director & 18 \\
IE & Chartered Arch. & Regulatory & Deputy Director & 25 \\
IF & Chartered Eng. & Regulatory & Director & 28 \\
IG & Chartered Eng. & Contractor & General Manager & 30 \\
IH & Chartered Eng. & Contractor & Project Manager & 17 \\
\hline
\end{tabular}

\section{RESEARCH FINDINGS}

\subsection{INTERPRET INFORMALITY OF BUILDING CONSTRUCTION}

In order to interpret the informality in building construction, level of obtaining certain approvals, regulatory actions and other requirements were disclosed though the samples selected. Figure 3 demonstrates that $100 \%$ of the respondents has obtained Development permit for construction. Next, $28 \%$ of the respondents had worked according to the approved plans while $66 \%$ of the respondents had not work along with the approved plans. In addition, changes to the plans with approvals were done by $12 \%$ of the respondents and $88 \%$ of the respondents had not approved the changes that arose after the approvals.

Thereafter, examined the level of acquiring Certificate of Completion COC to the buildings and $56 \%$ has acquired COC while $44 \%$ had not acquired COC. Even after receiving the $\mathrm{COC}$ some building owners tend to continue building construction activities illegally. With that context, $82 \%$ of the respondents had not done any developments after acquiring COC and $18 \%$ of the respondents has done changes to their buildings. Finally, illustrates whether the contractors of selected building samples were registered under CIDA or not. According to the respondents, $24 \%$ of the contractors were registered under CIDA and remaining 76\% was not registered under CIDA.

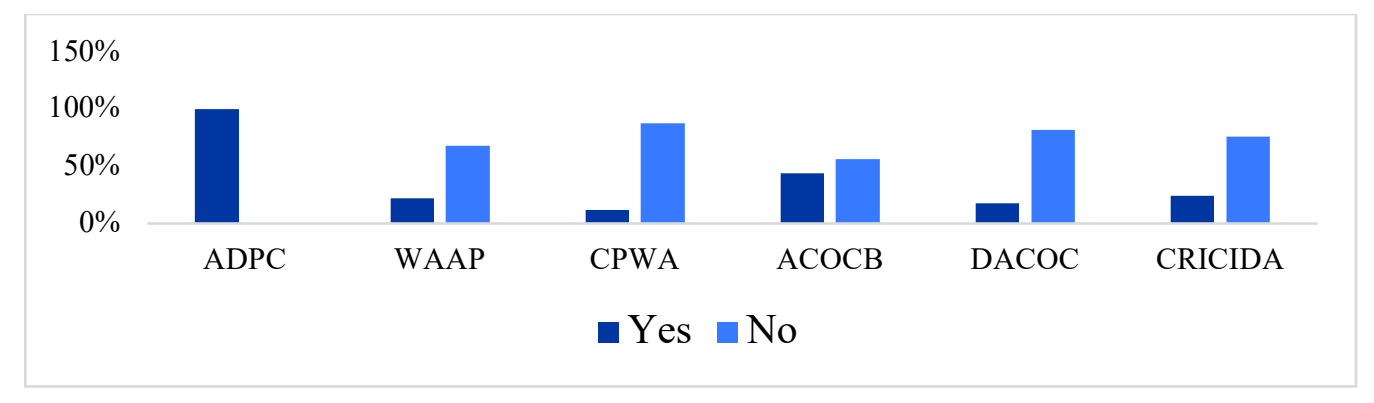

Figure 3: Level of followed regulatory procedures 
Legend: ADPC-Acquired Development Permit for Construction, WAAP-Work According to Approved Plan, CPWA-Carried out changes to the Plan with Approvals, ACOCB-Acquired COC for Building, DAACOC-Development after Acquiring COC, CRICIDA-Contractor Registered in CIDA

Using above details, the informal and formal building constructions in the building sector was determined. The situations where development permits were not obtained, construction work were not conducted according to the approved plans, changes were carried out to the plan without approvals, COC were not acquired to the buildings at completion, development after acquiring COC and where the involved contractor is not registered under CIDA were considered as features in the informal constructions. Therefore, the selected sample was divided into informal constructions and formal constructions as shown in Figure 4.

Therefore, according to the above differentiation the selected sample of 50 buildings were divided. From the selected 50 sample, 38 were identified as informal building constructions.

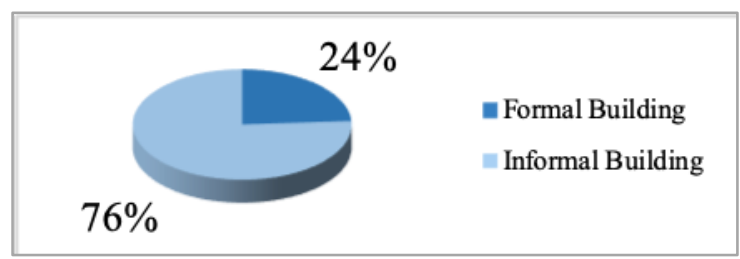

Figure 4: Differentiating informal and formal constructions

\subsection{REASONS TO INFORMALITY IN BUILDING CONSTRUCTIONS}

Through the questionnaire survey, respondents presented their reasoning for not complying to the regulatory requirements.

- Reasons for not taking approvals for the changes carried out

Reasons not to comply work with approved plan:

The clients' main reasons for not compiling to the approved plan was changes in the requirements. Thereafter, the second most consideration was to minimise the cost. Then moderate opinion on not compiling to the approved plan was the client objective for design was only to acquire approvals. The least concerns not to comply with approved plan was contractor implemented changes and space optimisation respectively. With such determinations, clients do not tend to take approvals for changes carried out after receiving approvals.

$\underline{\text { Reasons for not taking approvals for the changes carried out: }}$

Most respondents' rationale was that they did not concerned about this factor. Secondly, the decision of not taking approvals were due to the time consumption. Since the changes were illegal the respondents did not want to take approvals to their changes considered as the third common answer among the respondents. Respectively reluctance to be served by government organisations and clients were not aware were least concerned factors on not taking approvals for changes according to the sample respondents.

- Reasons not to acquire COC

The most common reason not to acquire COC is client do not have generic need to obtain COC. Accordingly, second most common reasoning was additional cost required and 
reluctance to be served by government organisation. Elaborating that, clients do not mentally positive about the service given by the government organisation. Therefore, they do not tend to acquire their services. Seven number of responses received stating that clients did not concerned about acquiring changes. Subsequently, four responses stated that they had not approved the changes carried out.

- Reasons to development after acquiring COC

Two reasons were identified concerning the development carried out after acquiring COC. The most common cause for construct beyond the regulations and the other cause identified was changes in the requirements.

\subsection{SUGGESTIONS TO INCREASE FORMALITY IN THE INFORMAL BUILDING CONSTRUCTIONS}

Mainly these suggestions are focuses on two categories. One is towards clients to improve awareness and other on regulatory bodies to increase the active involvement of the regulatory bodies through professionals to minimise informal construction in order to drive out the adverse effects such as building defects and collapses.

Acquiring $\mathrm{COC}$ for building constructed is existing regulations in the construction industry. Even though that practice less in the society. In order to establish acquiring COC experts suggested to issue COC through periodical reinvestigations. Further, from the client side the mechanisms to aware people should improve. Moreover, regulatory bodies can take step ahead and restrict providing service connections to the building without COC. Even though it requires proper coordination and effective mechanism between the regulatory bodies and service providers.

However, even after acquiring COC, people tend to carry out development activities. Therefore, experts suggested to carry out the periodical reinvestigations even after the construction stage. However, factors such as client ignorance, time consumed required to be addressed. In additions, contractors also required to motivated to register under CIDA for control the contractors' effect on the Sri Lankan construction industry. In enhance the formality in the construction this is another major requirement. Even though client side support to promote registering contractors in CIDA is very less because there consideration on the selection of contractor laid least focus on the CIDA registration. Further, formality can be increased through usage of the contract document. The factors evolved though the questionnaire survey stated not usage of contract document as a cause to failure outcome in the informal building construction. Therefore, regulations were focused to adopt regulations strictly to increase the use of contract document and aware informal contractor.

\subsection{PROFESSIONAL INVOLVEMENT IN INFORMAL CONSTRUCTIONS}

In the informal construction sector, the professionals' involvement is mostly concerned in order to take approvals, license endorsement or necessary clearance from the local authorities (Jewell et al., 2005). The findings emerged through this study had similar idea and further elaborated cost of professional consultancy service is the most critical influence to not involved professionals. Experts interviewed in this research tied that opinion stating professionals mostly involved only to the planning activities in the informal building constructions. 
However, to enhance the quality of the building facility it is required the involvement of the construction professionals to the construction stage of the building. Further, experts suggested to periodical certification to the construction stage buildings in order to ensure the quality of the construction delivery. Even though this certification systems can fail to deliver proper services. Therefore, professional bodies proposed to tie up the professionals to conduct proper functioning. Other than that, professional involvement can be integrated to the informal construction through integrating competent professionals responsible for their competent areas.

According to the questionnaire survey findings, "Cost of professional fees" was a major concern of clients when selecting consultants. Further, qualification of the professionals was another criterion of concern. On the other hand, experts stated that client engaged with informal construction activities are mostly unaware about the qualified professionals. However, experts suggested national involvement by controlling professional fees and providing incentives to low income people to obtain professional services. In local context, "Cost on contractor selection" with RII value of 0.93 was identified as the most crucial factor on the selection of contractor to the industry, which was similarly stated in literature. Subsequently, findings showed that client considered 'Quality of the work carried out' as a critical factor with RII of 0.77 . This statement was confirmed through the experts' opinion, which stated Sri Lankan construction clients are more cost oriented. Casual basis and temporary workers were more common in the informal construction (Mlinga and Lema, 2011). Therefore, lesser standards of working can be identified in informal constructions according to the existing literature. When selecting the contractors but the consideration on 'Sufficiency of resources' was less with RII of 0.34 . That elaborates even the local client concern quality of buildings they do not concern about other root causes for quality work. Moreover, contractors registered under CIDA has to pay several taxes. Further, literature existing elaborated in international context cost of registration to regulatory bodies are higher therefore small contractors does not tend to register Accordingly, findings displayed that the 'Registered in CIDA' for contractor as non-crucial factor with RII value 0.21 on the selection of the contractors in the informal construction industry. Research findings from expert interviews elaborated there is a need of professional enhance involvement to the construction industry. Further, experts suggested to enhance involvement of the professionals through establishing legal responsibility on the professionals with the activities such as designing, material suggesting, structural designing and plan approving.

\subsection{EFFECT OF REGULATORY BODIES FOR INFORMAL BUILDING CONSTRUCTION IN SRI LANKA}

Currently, CIDA, Urban Development Authority (UDA) and Local authorities are governing the construction activities in the local context. Since the informal constructions are deep rooted to the local construction context, some of the experts stated that it is difficult to drive out informal construction from the industry. Additionally, almost all the constructions carried out in the country not regulated through these regulatory bodies. Other than that informal construction activities are mostly, do not follow rules and regulations stipulated by the statutory bodies.

Experts interviewed stated that in relation to the construction rules and regulations, there is a requirement of control mechanisms in the Sri Lankan construction industry. Further, they suggested that it should initiated at the early construction stages and flows 
throughout the building life cycle in order to maintain standards of building and its functionality.

Table 2: Action procedure of suggested regulatory body

\begin{tabular}{|c|c|}
\hline Stage & Action \\
\hline Design stage & $\begin{array}{l}\text { Do pre investigation and check deign quality. Then provide approval. } \\
\text { Take design responsibility }\end{array}$ \\
\hline $\begin{array}{l}\text { Construction } \\
\text { stage }\end{array}$ & In each milestone should visit site and certify construction conditions \\
\hline \multirow{3}{*}{$\begin{array}{l}\text { Operation and } \\
\text { maintenance } \\
\text { stage }\end{array}$} & Should inspect the completed construction project at handing over stage. \\
\hline & $\begin{array}{l}\text { Regulatory body to periodically inspect the buildings to check whether } \\
\text { changes done had obtained approvals, maintenance done up to the } \\
\text { standards and whether there are defects }\end{array}$ \\
\hline & $\begin{array}{l}\text { Along with that, such regulatory body considered to force getting } \\
\text { approvals for changes, maintain regular maintenance, take remedial } \\
\text { actions to defects and instruct to demolish if the construction building is } \\
\text { illegal }\end{array}$ \\
\hline
\end{tabular}

Experts opinion about informal construction is it should be driven out in the construction practice. Moreover, identified few options that can be followed in order to drive out this wrong practice. Current regulations should change, increase reinvestigation and changes should be made to thinking patterns in society.

\section{THE CONCEPTUAL FRAMEWORK TO CONTROL INFORMAL BUILDING CONSTRUCTION IN SRI LANKA}

The conceptual framework was developed from the research findings on the demarcations of the building informality, causations to building performance due to informal construction and building defects, which identified along with the remedial actions. Other than that, the conceptual framework integrated the strategies to minimise the building informal constructions and building defects and collapses and showed the relationships in between. The developed framework is illustrated in Figure 5.

\section{CONCLUSIONS AND RECOMMENDATIONS}

According to the findings, from the research informal building constructions deep rooted in the Sri Lanka. Event there are already established regulatory bodies to govern the construction industry there is a need of controlling the informal constructions. In this research context, the clients who directly employee the skilled and non-skilled labourers and construct own buildings mostly houses were not considered to the selected research area. However, this research recommends the followings in order to drive out informal construction practices,

Firstly, informal constructions should be driven out from the construction industry. In order to that, need to change the existing rules and regulations and expand the professionals' involvement through investigations have to be carried out in the design, construction and operation stages without limiting it to planning stages. 


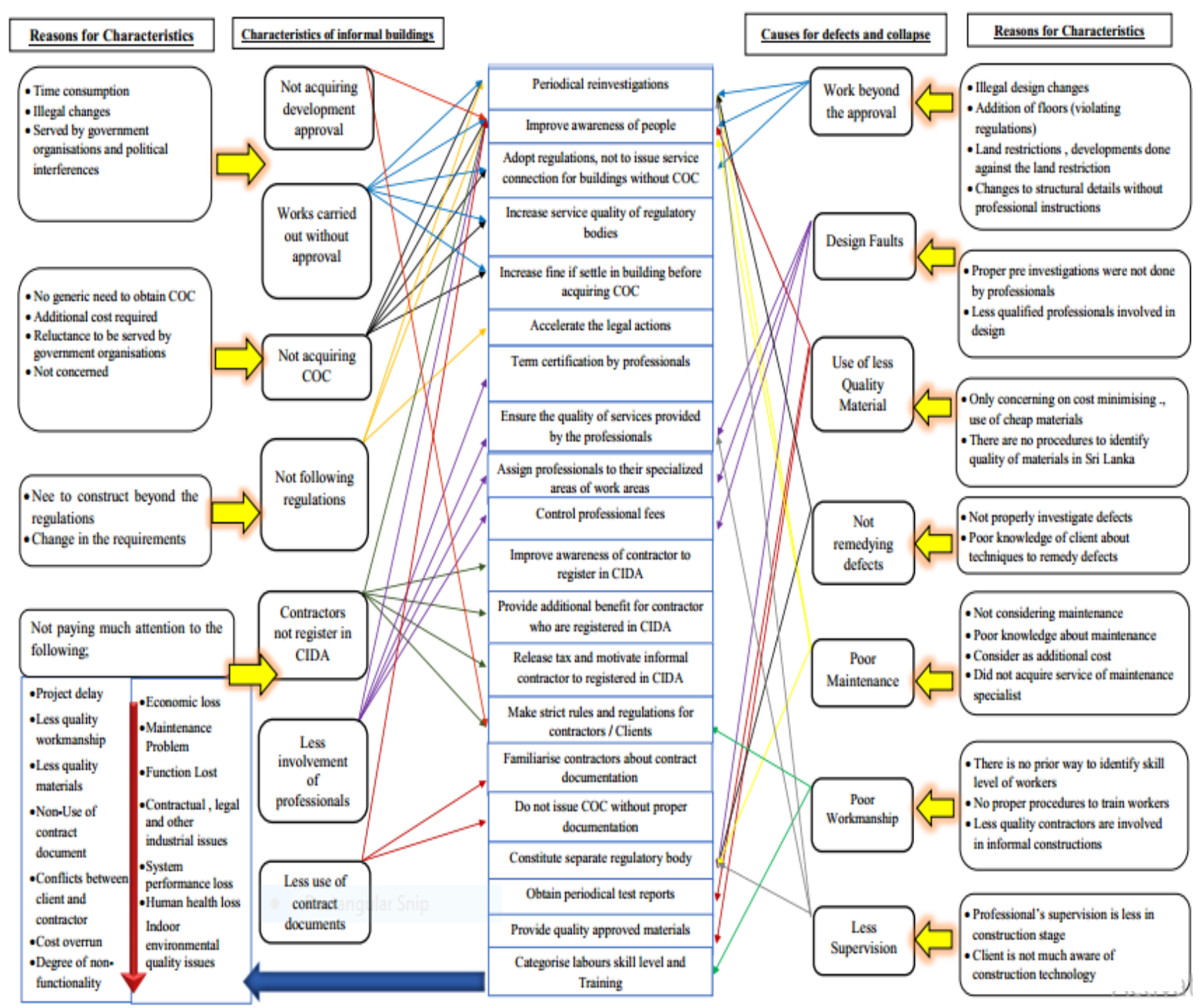

Figure 5: Conceptual framework to control informal building construction in Sri Lanka

Generally, informal building construction practices not acquire COC at the completion of the construction. Therefore, in order to promote $\mathrm{COC}$ acquiring regulatory bodies can be integrated with the national service providing bodies such as water and electricity and adopt regulations to demand COC for providing services. Professional involvement should be properly addressed the informal building constructions with the collaboration of the professional bodies existing. The professional bodies should have guided and categorise professionals under their specialised areas in order to provide comprehensive solutions to the informal construction activities in the local context.

Legal action taking processes should be sped up in order to erase the conventional ideas of the clients such as reluctance to obtain national services provided due to lengthy time taking procedures. In terms of contractors, should implement mechanisms like tax exemptions to attract them to follow regulations such as registering in CIDA. Furthermore, separate regulatory body can be established in order to involve with the construction activities from the project inception stage to the disposal stage. Through continuous controlling mechanisms can improve the standards of the building 
constructions as well as improve the building functionality. Above suggestions are categorised with causations and characteristics of the informal building construction in the conceptual framework to control informal building construction in Sri Lanka.

\section{REFERENCES}

Adnam, Y. M., Dand, M. D., Ahmad, A. B., Anic, A. B., and Aziz, D. 2009. Determining the criteria for the classification of purpose built office buildings in Malaysia. Pacific Rim Property Research Journal, 15(2), pp.225-243

Ahzahar, N., Karim, N. A., Hassan, S. H., and Eman, J., (2011). A study of contribution factors to building failures and defects in construction industry. Procedia Engineering, 20, pp.249-255.

Blades, D., Ferreira, F. H., and Lugo, M. A. (2011). The informal economy in developing countries an introduction. International Association for Research in Income and Wealth. Malden: Blackwell publishing

Chamber of Construction Industry Sri Lanka. (2017, June). Eyes and ears of key construction issues. Construction review, 15(27), pp.1 . Available from http:/www.ccisrilanka.org/2017/06/30/cci-bulletinjune-2017/\#june-2017/page1

Chandrasena, G.L., 2010. Importance of quality assurance in the building construction industry of Sri Lanka. National Building research organization: Sri Lanka.

Chong, A., Galdo, J., and Saavendra, J. (2008). Informality and productivity in the labor market in Peru. Journal of Economic Policy Reform, 11(4), pp.229-245. doi:10.1080/17487870802543480

Gerxhani, K. (2004). Informal sector in developed and less developed countries: A literature survey. Public Choice, 120(3/4), pp.267-300. doi:10.1023/b:puch.0000044287.88147.5e

Hughes, D., Wiliams, T. and Ren, Z., 2012. Differing perspectives on collaboration in construction. Construction Innovation, 12(3), pp.355-368

Jewel, C., Flanagan, R., and Cattell, K. (2005). The effects of the informal sector on construction. Construction Research Congress. doi:10.1061/40754(183)78

Konig, H. and Cristofaro, M. L., 2012. Benchmarks for life cycle costs and life cycle assessment of residential buildings. Building Reserch \& Information, pp.558-580

Lerociyani, J., Jeevanarth, T., Thushyanthy, S. and Dissanayake, P., 2013. Informal construction sectar and Its Efects on the construction industry of Sri Lanka. University of Moratuwa, Sri Lanka.

Ludlow, N. P., and Neuhold, C. (2017). The Informal Construction of Europe. In proceedings with the 13th History of European Integration Research Society (HEIRS) Conference. Luxemburg

Mlinga, R. S. and Lema, N. M., 2011. Informal contractors in Tanzania-their characteristics and reasons for informality. Botswana, s.n.

Mlinga, R. S., and Wells, J. (2002). Collaboration between formal and informal enterprises in the construction sector in Tanzania. Habitat International, 26(2), pp.269-280. doi:10.1016/s01973975(01)00048-0

Overa, R. (2004). The creation of African urban livelihoods in between the formal and informal city. Forum for Development Studies, 32(2), pp.423-429

Pedro, J. B., Meijer, F. and Visscher, H., 2009. The Portuguese building regulation system: a critical review. International Journal of Law in the Built Environment, 1(2), pp. pp.156-171

Sandaratne, N., 2002. The informal sector in Sri Lanka its nature and extent and the Impact of globalisation, Colombo.

Wells, J. (2007). Informality in the construction sector in developing countries. Construction Management and Economics, 25(1), pp.87-93. doi:10.1080/01446190600601339

Wetlesen, A. (2011). Legal empowerment of workers in the informal economy: the case of the construction industry in Tamil Nadu, India. Journal of Asian Public Policy, 3(3), pp.294-308.

Yeboah, I. E., 2012. What is informal about the informal sector? culture and the construction of development in sub Saharan Africa. East African Geographical Review, 20(1), pp.1-10. 